\title{
Control Strategies of a Gas Turbine Generator: A Comparative Study
}

\author{
Lyes Abbassen ${ }^{1}$, Mustapha Zaouia ${ }^{2}$, Nacereddine Benamrouche ${ }^{3}$, Amar Bousbaine ${ }^{4}$ \\ 1, 2,3 Laboratory of Advanced Technologies in Electrical Engineering, University Mouloud Mammeri of Tizi Ouzou, \\ Tizi Ouzou, 15000 Algeria \\ ${ }^{4}$ University of Derby, College of Engineering and Technology, Markeaton street, Derby, DE22 3AW, UK \\ SONATRACH Direction Centrale Recherche et Développement DC- R\&D, Boumerdes, Algeria
}

\begin{tabular}{l} 
Article Info \\
\hline Article history: \\
Received Jan 22, 2020 \\
Revised Oct 2, 2020 \\
Accepted Nov 6, 2020 \\
\hline
\end{tabular}

\section{Keywords:}

Gas turbine

Rotor Generator

PID Controller

FLC Controller

FLC-PID Controller

Hybrid Controller

\begin{abstract}
Gas turbine generators are commonly used in oil and gas industries due to their robustness and association with other operating systems in the combined cycles. The electrical generators may become unstable under severe load fluctuations. For these reasons, maintaining the stability is paramount to ensure continuous functionality. This paper deals with the modeling and simulation of a single shaft gas turbine generator using the model developed by Rowen and incorporating different types of controllers, viz a Zeigler- Nichols PID controller, a Fuzzy Logic Controller (FLC), FLC-PID and finally a hybrid PID/FLC/FLC-PID controller. The study was undertaken under Matlab / Simulink environment with data related to an in-service power plant owned by Sonatrach, Algiers, Algeria. The results show that FLC-PID and hybrid tuned controllers provide the best time domain performances.
\end{abstract}

Copyright (C) 2020 Institute of Advanced Engineering and Science. All rights reserved.

\section{Corresponding Author:}

Mustapha ZAOUIA

Laboratory of Advanced Technologies in Electrical Engineering, University Mouloud Mammeri of TiziOuzou, TiziOuzou, 15000 Algeria

Email: zbmust@yahoo.fr

\section{INTRODUCTION}

In most refineries, cogeneration is very often used to generate electricity and to provide steam for the processing units. Power generation plants, which are usually interconnected with utilities, have very complicated structures with some inherent problems associated with power and voltage oscillations caused by the different connected loads and particularly high power induction motors. These problems seriously affect power plant operations and may even lead to a blackout. To facilitate the design and analysis of such complex systems, modeling and simulation are required.

Rowen has developed a model based on the concept of the transfer function for a heavy duty gas turbine in 1983 [1]. This model was verified by simulation by [2], and subsequently used to study the dynamic analysis of combined cycle plants [3], twin shaft gas turbine plant [4] and even micro gas turbine plants [5]. From the control point of view, Rowen and Hannet et al. contributions used conventional fixed gain PI controllers for speed, temperature and acceleration controllers. Later Grosa et al. [6] and Camporeale et al. [7] introduced non-linear lumped parameter models to decouple the interaction between the speed and the exhaust temperature loops. To achieve this, a precise dynamic model and an accurate transfer function of the gas turbine are required, which are very difficult to achieve in practice without extensive tests and extensive expertise. 
This paper deals with the dynamic modelling and simulation using Matlab/ simulink of a single shaft gas turbine by reconsidering the model developed by Rowen and incorporating four controllers: a classical Zeigler- Nichols PID controller, a Fuzzy Logic Controller, a Fuzzy Logic-PID Controller (FLC-PID), and a hybrid PID/FLC/FLC-PID controller. The results show that the controller tuned using FLC-PID and hybrid Fuzzy-PID/PID are the best in considering the performances of the system.

\section{GAS TURBINE MODELLING}

The schematic diagram of a simple-cycle single shaft gas turbine which is designed to operate at higher speeds, typically in the range of 50,000-120,000 rpm, is shown in Figure 1[1]. It consists of an axial air compressor, so the entering air temperature is raised; and a combustion chamber where fuel and air are injected. This followed by the turbines, which develop a rotary mechanical torque to drive a synchronous generator [2].

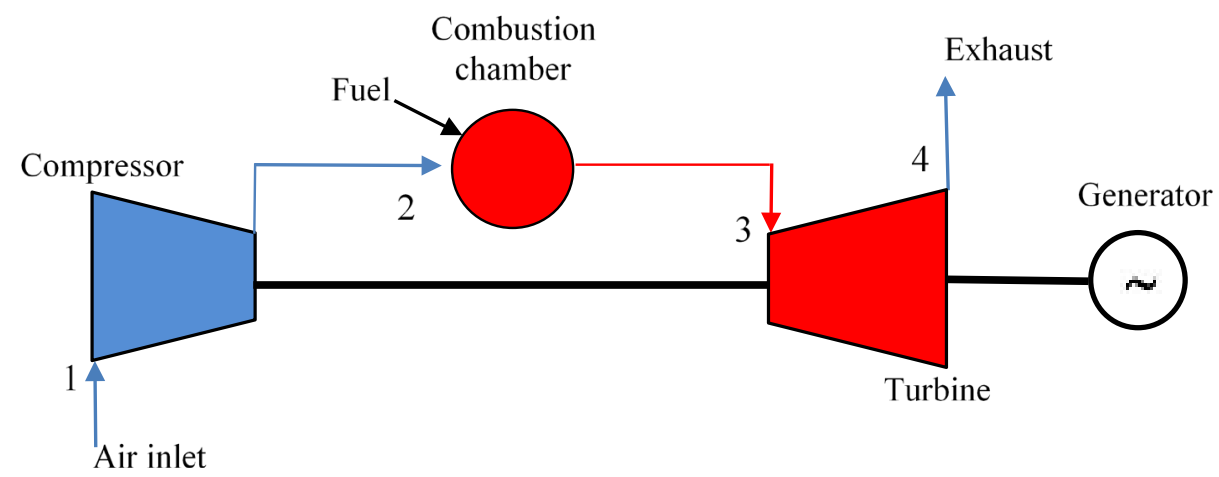

Figure.1. A simple-cycle gas turbine

In 1983, Rowen [1] has developed a simplified model of a gas turbine, which may be considered as a reference and alsoreconsidered by many other researchers in their investigations [2-7]. It consists of a set of algebraic equations describing the steady state characteristics of a gas turbine $[3,4]$. This model is represented in Figure 2.

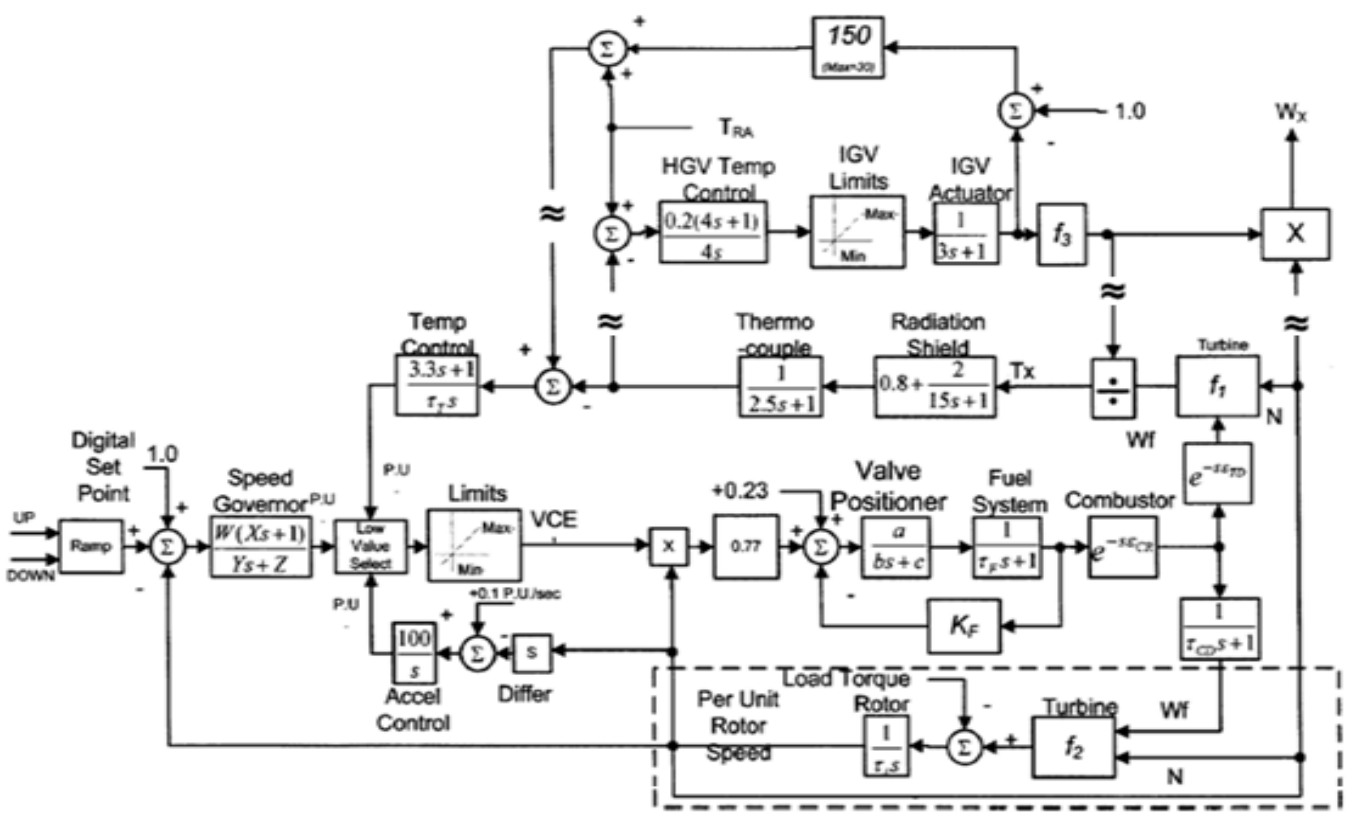

Figure 2. Rowen model of a gas turbine

This model was introduced by Rowen in [3] and completed in [8]. The main industrial gas turbine components are the compressor, the combustion chamber and the turbine operating under the Brayton cycle [9], that it can be divided into two interconnected subsystems [10]- [12]. Three important regulators are used, the first to control the (speed/ power) under partial load conditions, the second to control the temperature controller and the third to control the acceleration. 


\subsection{The fuel system}

The fuel system consists of the fuel valve and the actuator, which can be modeled by the following equation [13], [14].

$w_{f}=\frac{k_{f}}{\tau_{f}+1} \cdot e_{1}$

Where $w_{f}$ is the gas turbine fuel flow (per unit), $k_{f}$ fuel system gain constant, $e_{1}$ valve position and $\tau_{f}$ fuel system time constant.

\subsection{The valve positionner}

The valve positionnerequation is given by:

$e_{1}=\frac{a}{b s+c} \cdot F_{d}$

Where $F_{d}$ is the input variable to the fuel system (per unit) and (a, b, c) are the cofficients of the fuel system transfer function.

\subsection{The turbine functions}

The turbine torque, the exhaust temperature and the air flow rate denoted in Figure 2 respectively $f_{1}, f_{2}$ and $f_{3}$ are calculated using the following equations [15]:

$f_{1}=1.3 \cdot\left(w_{f}-0.23\right)+\frac{1}{2} \cdot(1-\Delta w r)$

$f_{2}=T_{r}-700 .\left(1-w_{f}\right)+550 .(1-w r)$

$f_{3}=w r *\left[\frac{519}{T a+460}\right] *(\operatorname{Ligv})^{0.257}$

Where wris the per unit turbine rotor speed, $T_{r}$ is the rated exhaust temperature and $\Delta w r$ is the diviation speed.

\subsection{The rotor function}

The rotor time constant of a gas turbine power plant varies in a wide range from 12.2 to 25.2 as given by Rowen. Therefore, there is a need to optimize the rotor time constant along with the droop setting value. The equation of setting the time constant is written as a function of both droop setting (S) and rotor time constant $(\tau)$ as variables as follows:

$T_{o p}=17.594-2.346-0.4497+0.155 \mathrm{~s}^{2}+0.014 . \tau^{2}+0.004 . \tau \mathrm{s}$

During normal operating conditions, frequency and power are the two fundamental variables controlled by the main control loop [16-19]. When the operations of the system change, or become abnormal, the temperature and acceleration controllers are activated. However, under normal operating conditions, the Rowen model can be further simplified by neglecting the acceleration and the temperature controllers. The speed / power regulator becomesthenthe predominant. The transfer function of the simplified model under normal operating conditions is illustrated by Figure 3.

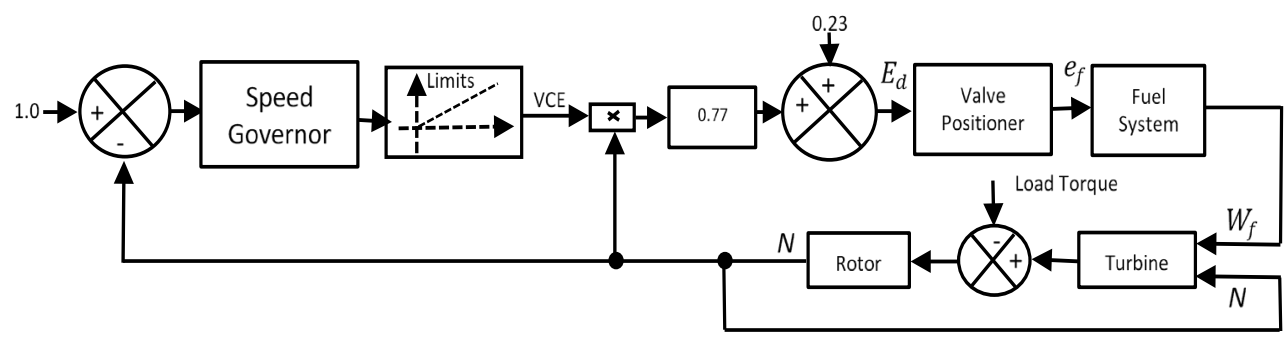

Figure 3. Simplified Rowen model under normal operation conditions

\section{CONTROL DESIGN AND ANALYSIS}

In industrial control systems, the classical regulator PID-ZN is often used. However, in this paper, a new design based on the fuzzy logic theory is introduced. In fact, a fuzzy logic controller, FLC-PID controller and ahybrid controller are used in order to improve the performances of the controlled system. The proposed regulators are shown in Figure 4. 


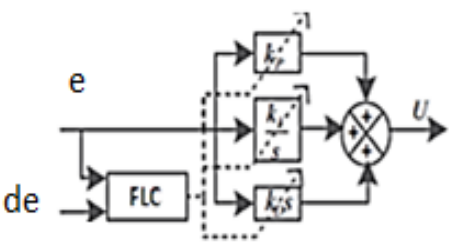

a

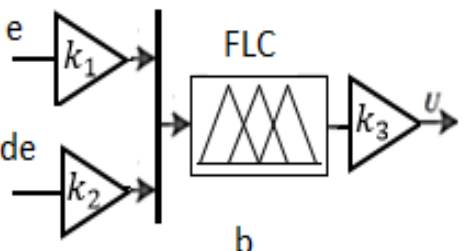

b

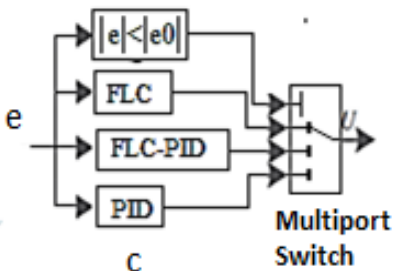

Figure 4. Controllers design: a) Fuzzy, b) FLC-PID and c) hybrid controllers

\subsection{Fuzzy logic Controller}

The simulink block and the meshgrid function of the FLC controller is shown in Figure 5.
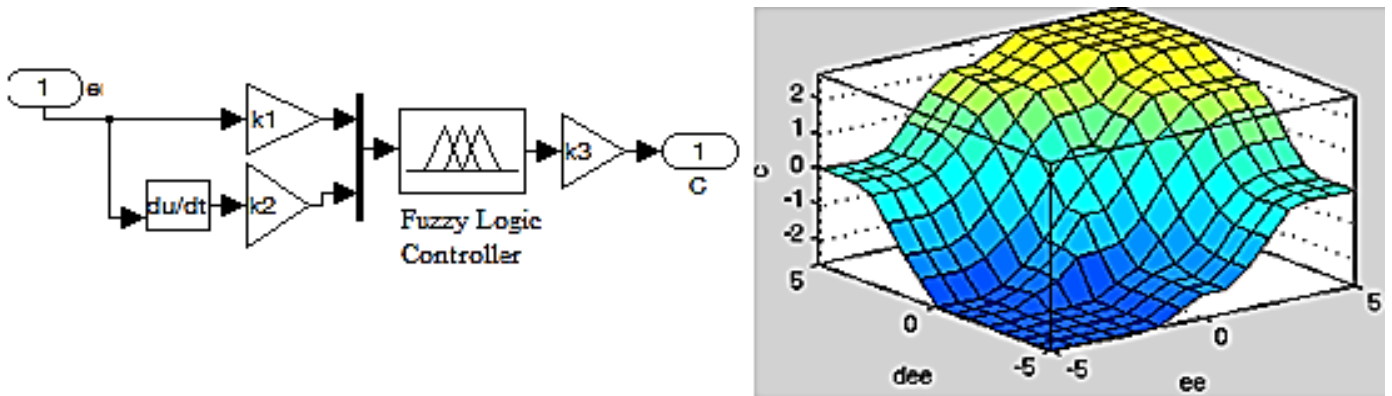

Figure 5. FLC Simulink block and meshgrid function

The designed FLC will determine the amount of fuel flow to the combustion chamber over its transient operation. The FLC and the available gas turbine constitute a closed loop. Figure 6 illustrates the process of the fuzzification and defuzzification for controller.

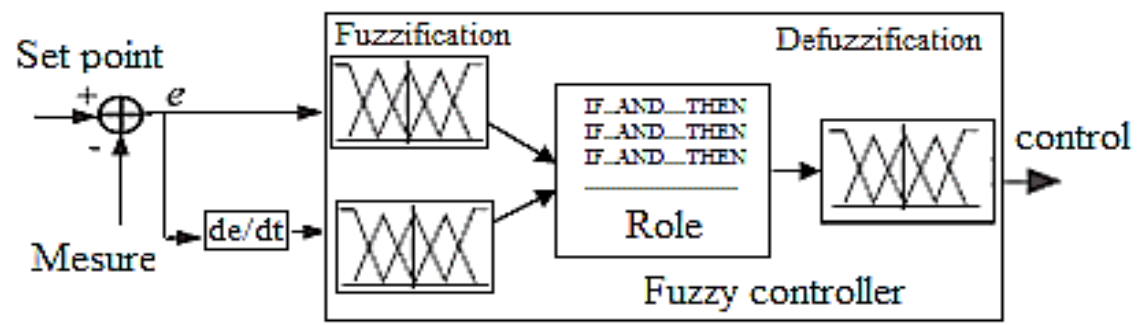

Figure 6. Implementation of the fuzzy controller

After fuzzifying of the input values, the controller uses the corresponding input linguistic terms and the rule base to determine the resulting linguistic terms of the output variables. Defuzzification is the process of converting the degrees of membership of the output linguistic variables within their linguistic terms into crisp numerical values [20]. The defined fuzzy function used in this paper for the first and the second input and the output of the fuzzy functions are given in Figure 7. Table 1 describes the fuzzy tuning rule for the FLC Controller.

Table 1. Speed FLC table control

\begin{tabular}{llllllll}
\hline \multicolumn{7}{c}{ dele } \\
\hline & NL & NM & NS & ZE & PS & PM & PL \\
NL & PL & PL & PL & PM & PM & PS & ZE \\
NM & PL & PM & PM & PM & PS & ZE & NS \\
NS & PL & PM & PS & PS & ZE & NS & NM \\
ZE & PM & PM & PS & ZE & NS & NM & NM \\
PS & PM & PS & ZE & NS & NS & NM & NL \\
PM & PS & ZE & NS & NM & NM & NM & NL \\
PL & ZE & NS & NM & NM & NL & NL & NL \\
\hline
\end{tabular}



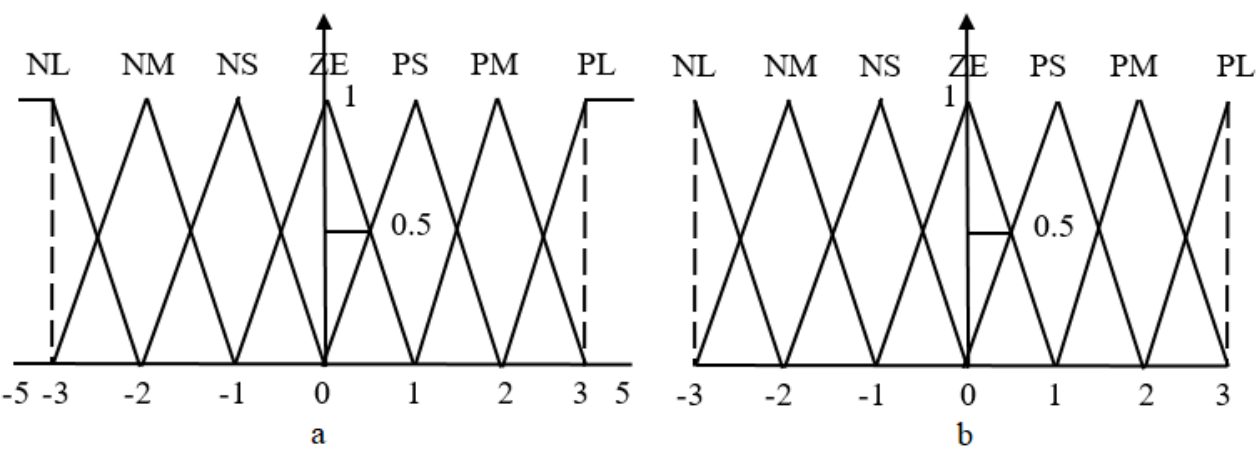

Figure 7. The Inputs and the output of the fuzzy functions, (a) X-e and de, (b) U.

\subsection{PID-Fuzzy Logic Controller}

Figure 8 shows the PID control system with a fuzzy gain scheduler. The approach taken here is to explore fuzzy rules and reasoning to generate the controller parameters. It is assumed that $K p, K d$ are in prescribed ranges respectively $\left[\left(K p_{\min }, K p_{\max }\right),\left(K d_{\min }, K d_{\max }\right)\right]$.

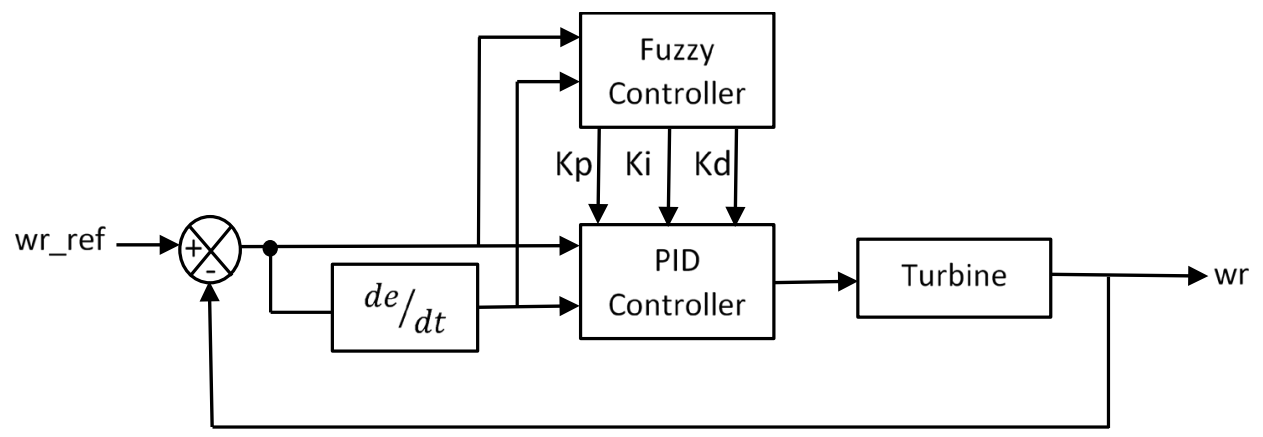

Figure 8.PID control system with Fuzzy gain scheduling by Figure 9

The Mamdani control process implemented under Matlab-Simulink of a fuzzy scheduler is illustrated

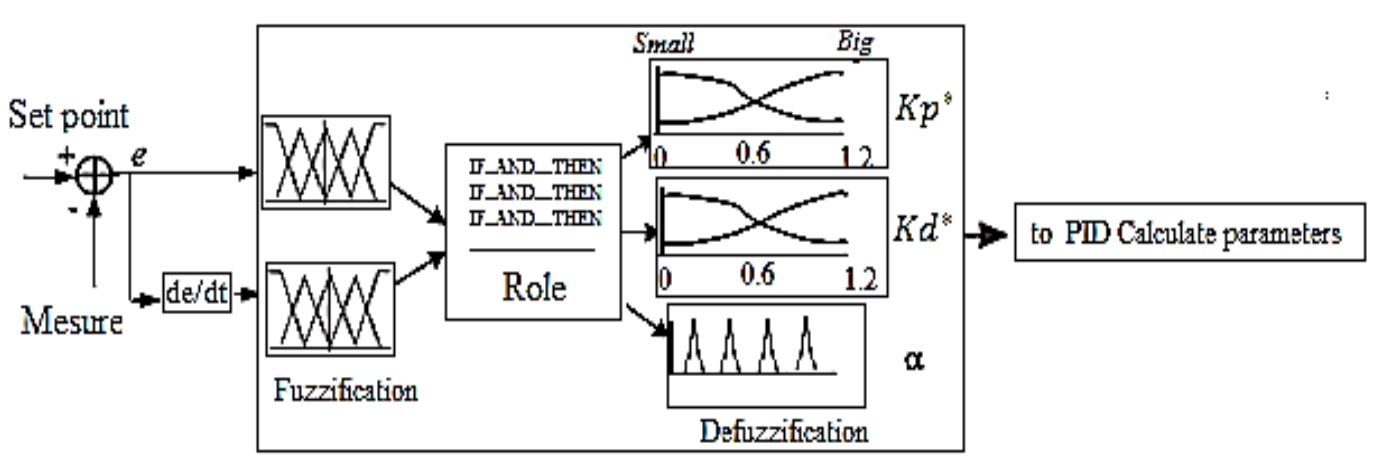

Figure 9 Implemention of the technical control strategy of the fuzzy gain scheduler

The parameters of the optimized PID controller are calculated using the following equations [21]- [24].

$$
\begin{aligned}
& K p=K p_{\text {min }}+\left(K p_{\text {max }}-K p_{\text {min }}\right) * K p^{*} \\
& K d=K d_{\text {min }}+\left(K d_{\text {max }}-K d_{\text {min }}\right) * K d^{*} \\
& K i=\frac{K p^{2}}{\alpha \cdot K d}
\end{aligned}
$$


Where $K p^{*}, K d^{*}$ and $\alpha$ are generated and determined by a set of fuzzy rules and as a function ofthe error and the variation of the error of the set speed. The fuzzy tuning rules for the fuzzy gain scheduler controller are described in Tables 2, 3 and 4.

Table 2. Fuzzy tuning rules for $K_{p}^{*}$

\begin{tabular}{lccccccc}
\hline & \multicolumn{1}{c}{ dele } \\
\hline & NB & NM & NS & ZE & PS & PM & PB \\
NB & S & S & S & S & S & S & S \\
NM & B & B & S & S & S & B & B \\
NS & B & B & B & S & B & B & B \\
ZE & B & B & B & B & B & B & B \\
PS & B & B & B & S & B & B & B \\
PM & B & B & S & S & S & B & B \\
PB & S & S & S & S & S & S & S \\
\hline
\end{tabular}

Table 3. Fuzzy tuning rules for $K_{d}^{*}$

\begin{tabular}{lccccccc}
\hline & \multicolumn{7}{c}{ dele } \\
\hline & NB & NM & NS & ZE & PS & PM & PB \\
NB & B & B & B & B & B & B & B \\
NM & S & B & S & B & S & B & S \\
NS & S & S & B & B & B & S & S \\
ZE & S & S & S & B & S & S & S \\
PS & S & S & B & B & B & S & S \\
PM & S & B & B & B & B & B & S \\
PB & B & B & B & B & B & B & B \\
\hline
\end{tabular}

Table 4. Fuzzy tuning rules for $\alpha$

\begin{tabular}{lccccccc}
\hline & \multicolumn{7}{c}{ dele } \\
\hline & NB & NM & NS & ZE & PS & PM & PB \\
NB & 2 & 2 & 2 & 2 & 2 & 2 & 2 \\
NM & 3 & 3 & 2 & 2 & 2 & 3 & 3 \\
NS & 4 & 3 & 3 & 2 & 3 & 3 & 4 \\
ZE & 5 & 4 & 3 & 3 & 3 & 4 & 5 \\
PS & 4 & 3 & 3 & 2 & 3 & 3 & 4 \\
PM & 3 & 3 & 2 & 2 & 2 & 3 & 3 \\
PB & 2 & 2 & 2 & 2 & 2 & 2 & 2 \\
\hline
\end{tabular}

The defined fuzzy functions used for the first and second input ( $e$ and $d e$ ) and the output of the fuzzy function are defined in Figure 10.
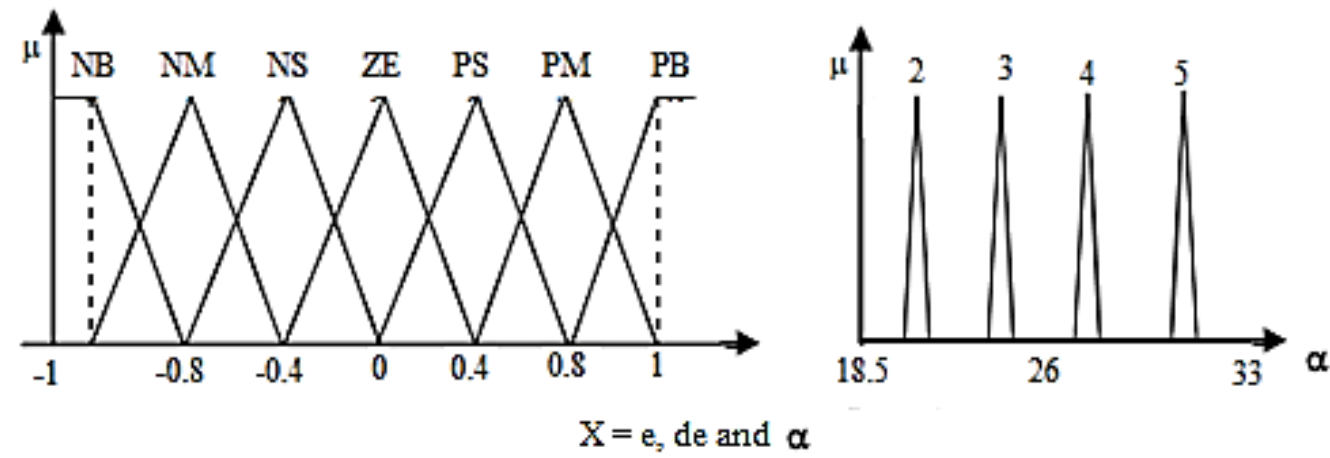

Figure 10 The Inputs and output of the fuzzy functions

The PID-Fuzzy gain scheduling block under Matlab-Simulink is given by Figure 11. It is constituted of three parts:

1- Fuzzy gain scheduler (Generate $K p^{*}, K d^{*}$ and $\alpha$ )

2- Optimized function (Calculate $K p, K i$ and $K d$ )

3- PID Controller 


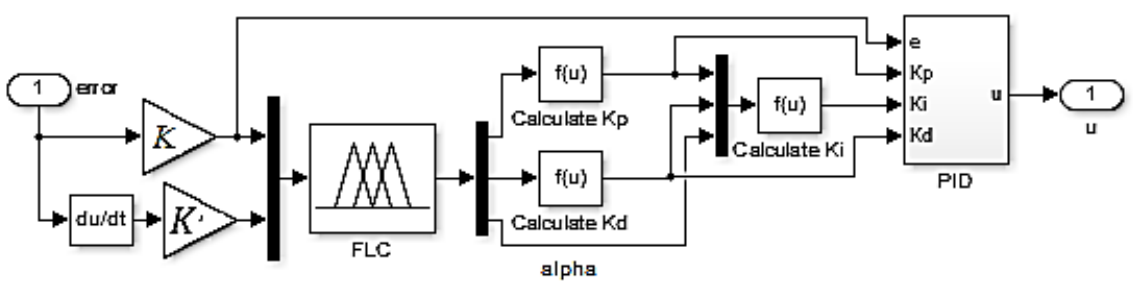

Figure 11 Simulink block of PID-Fuzzy gain scheduling

\subsection{Gain values of the controllers}

Table 5 gives the parameters for the different used controllers:

Table 5. The parameters of controllers

\begin{tabular}{clcl}
\hline Controllers & \multicolumn{3}{c}{ Gains controllers } \\
\hline PID & $\mathrm{kp}=45$ & $\mathrm{Ki}=0.5$ & $\mathrm{kd}=7.8$ \\
FLC-PID & $\mathrm{kp}=33.6905$ & $\mathrm{Ki}=0.4045$ & $\mathrm{kd}=8.8249$ \\
Fuzzy Gain & $\mathrm{K} 1=5 ;$ & $\mathrm{K} 2=1.5 ;$ & $\mathrm{K} 3=20$ \\
FLC-PID Gain & & $\mathrm{K}=5$ & \\
\hline
\end{tabular}

The PID controller is configured according to the method of Ziegler and Nichols; it allows a quick adjustment on the basis of the reading of the index response [22].

As a function of the error and the variation of the error generated between the reference and the measurement, the fuzzy controllerproduces a control signal, which is used to control the speed of the gas turbine. Multiplier coefficients can be added to amplify or attenuate the value of the inputs and the outputs within the limits of the operating ranges. The combination of FLC and PID allows to design other technical control systems. Depending on the error, the FLC readjusts and modifies the coefficients of the PID controller to improve the static and the dynamic performances.

\subsection{Hybrid Controller}

The hybrid controller is combined between three regulators (PID, FLC \& FLC-PID), a multiport switch is designed to select a regulator according to the absolute error to improve the static and the dynamic performances. It should be noted that each controller can be activated over a period in order to give the best performances.

The simulating block of the controlled speed and the power of the gas turbine under Matlab/Simulink is given by Figure 12 .

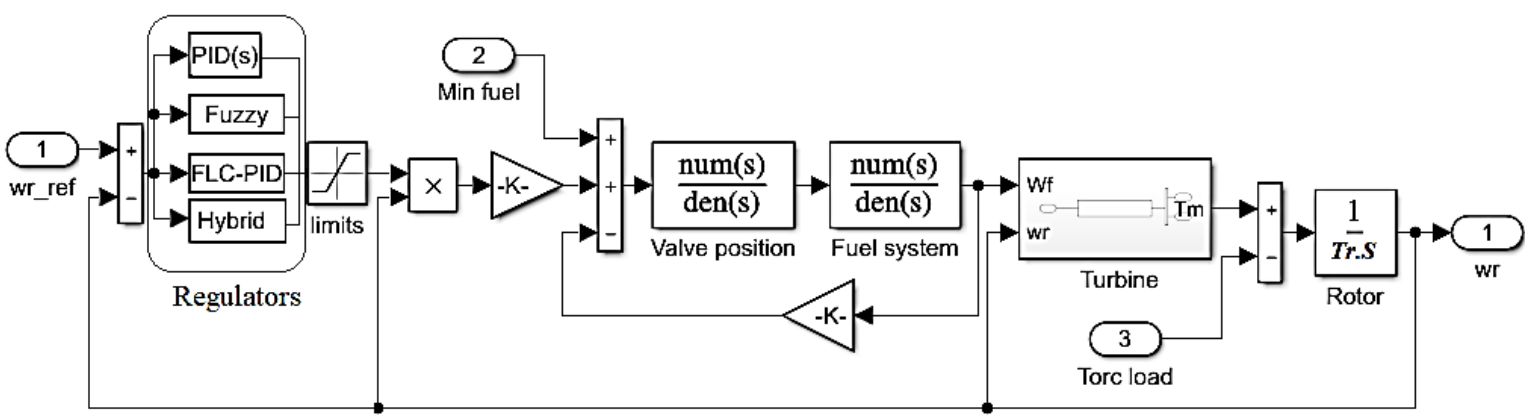

Figure 12 Simulink implementation of the controllers

\section{SIMULATION RESULTS AND ANALYSIS}

By changing the speed reference and the load, the dynamic responses of the speed and the power generated by the gas turbine (GT) are given by thecharacteristicsshown in Figures 13 and 14 for the different types of controllers. 
First the speed response of the GT is obtained by changing the speed references $(0.95,1$ and 1.05 per unit) and taking the load torque $\left(\mathrm{T}_{\text {load }}=0\right)$ and the results areillustrated by Figure 13.

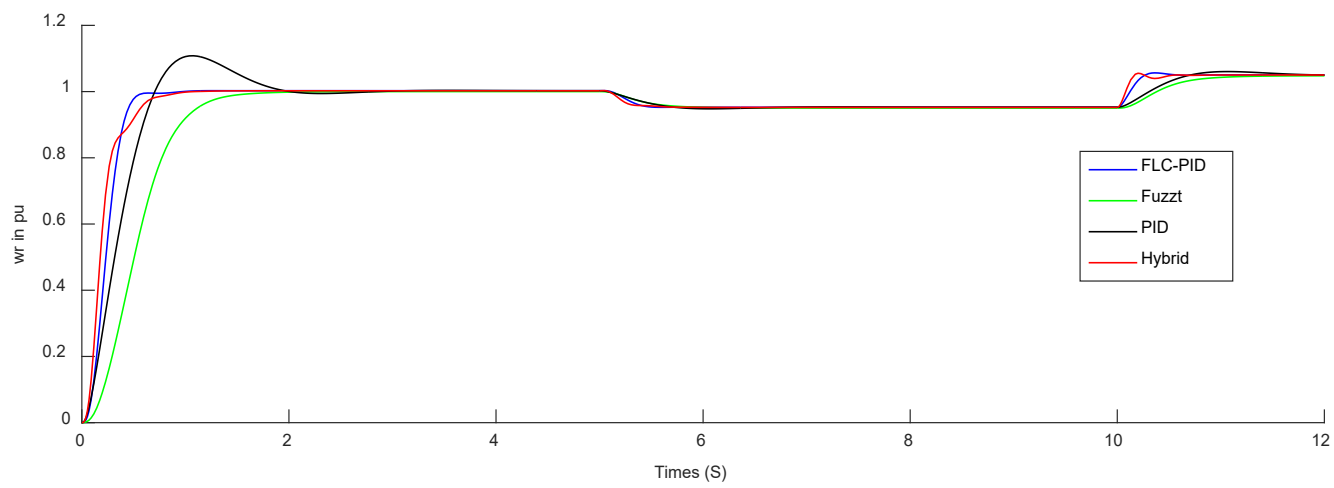

Figure 13. Speed responses comparison using different controllers

To study the performences of the regulators on load, the speed was set at 1 pu and introduce loads of $0.2,0.65$ and 0.4 per unit respectively at times $(\mathrm{t}=10 \mathrm{~s}, 15 \mathrm{~s}$ and $20 \mathrm{~s})$. It should be noted that the loads are introduced after the speed has reached its nominal value.

The speed and the power characteristics of the GT with the different regulators (PID, FLC, PID-FLC and hybrid) are presented in Figures 14 and 15.

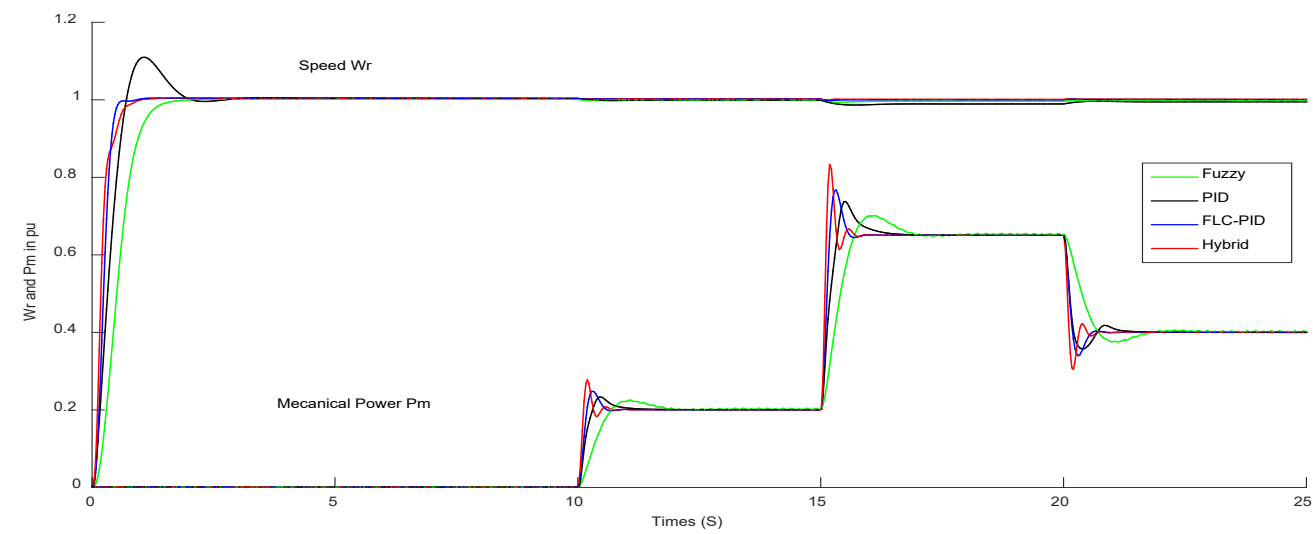

Figure 14 Comparison of speed and power responses of the Gas turbine using the Different Controllers
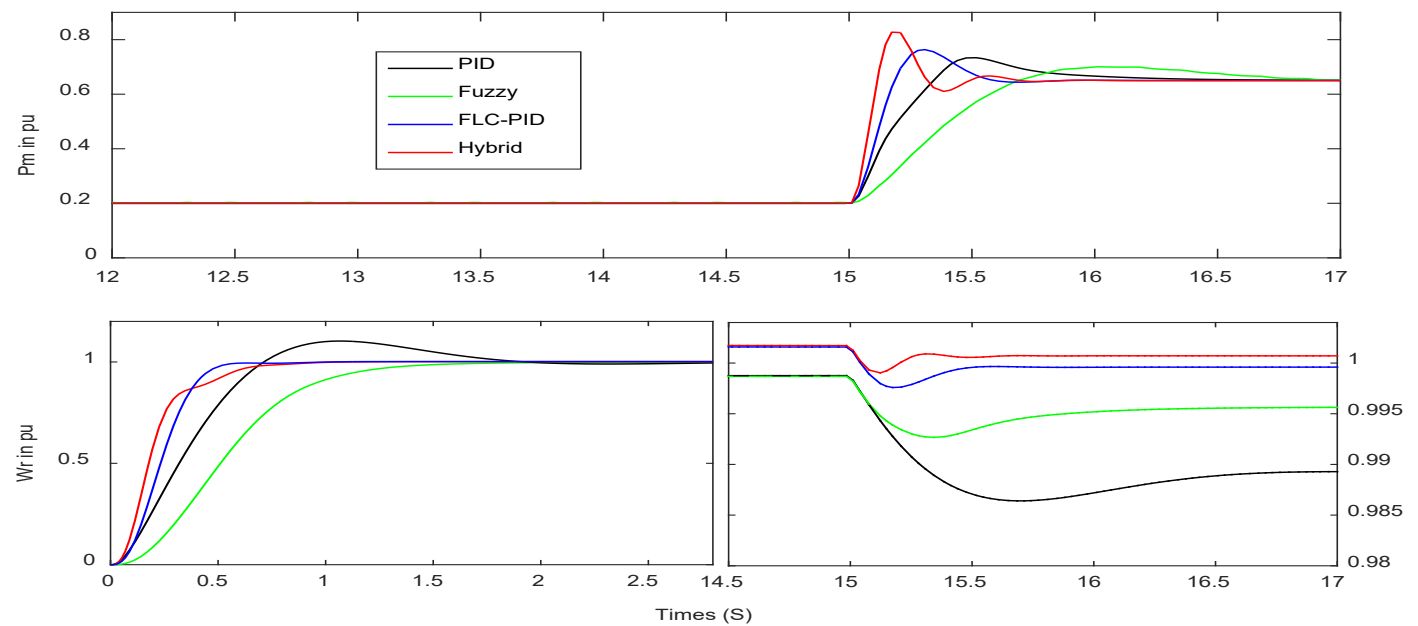

Figure 15 Zoom of the dynamic reponses of the speed and the power of the Gas turbine with the different controllers

These characteristics are comparable to those obtained by other researchers as presented in Figures 16 and 17 where the dynamic responses of the speed and the power are given as follows: 


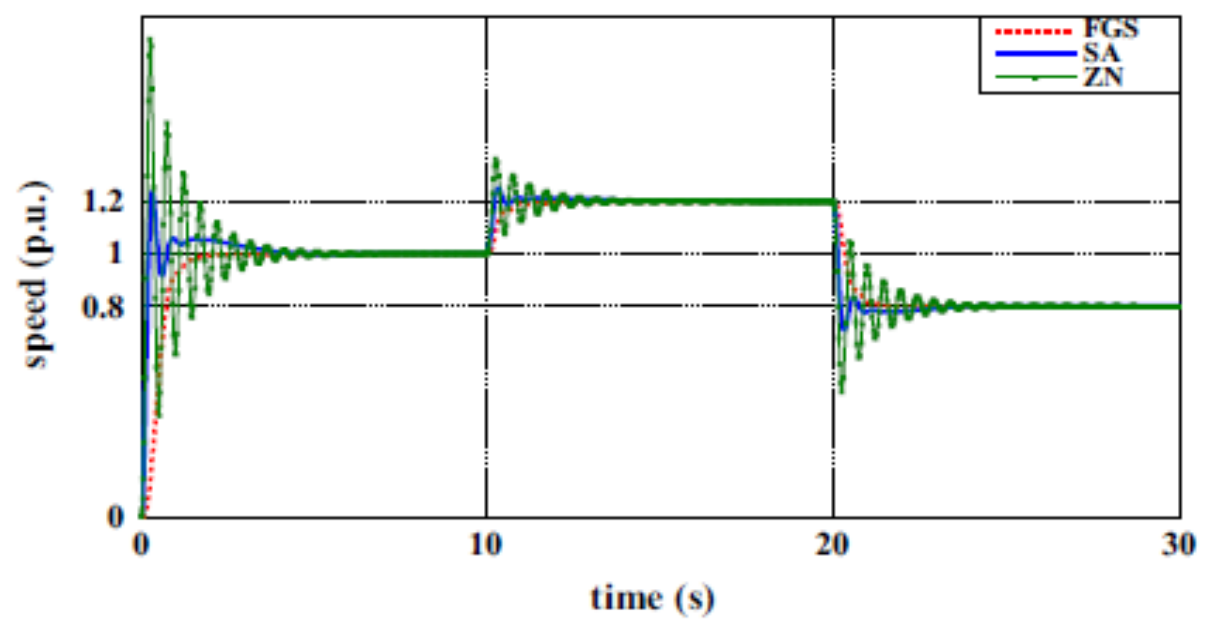

Figure 16 Large signal comparison analysis of gas turbine plant controlled by Ziegler Nichols (ZN), Simulated Annealing (SA) and Fuzzy Gain Scheduling (FGS) tuned PID controller [25]
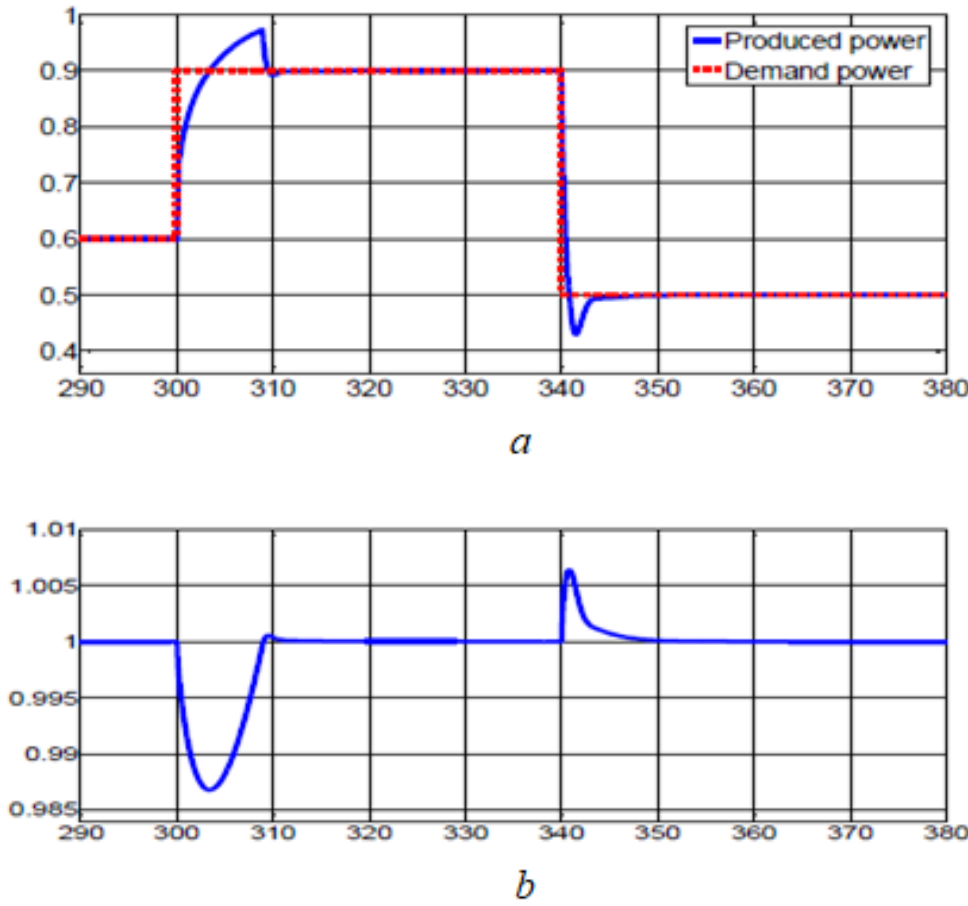

Figure 17 Dynamic response in the power demand and in the speed of a gas turbine controlled by Recurrent fuzzy-neural network controller [26].

As can be seen in Figures 14 and 15, a zero steady state error is achieved with all the controllers. However, for the dynamic responses, the fuzzy-PID logic controller and the hybrid controller responded faster as far as the speed time response is concerned with relatively a small overshoot resulting in a smooth speed response. The performances of a gas turbine are obtained using several controllers (PID-ZN, FLC, FLC-PID and Hybrid Controller). To validate our results, they are compared to those available in the literature [25-26] as seen in Figures 16 and 17. It is clear that the power and speed characteristics follow the same trend as those obtained in our paper.

\section{CONCLUSION}

In this paper, the model developed by Rowen for a gas turbine is reconsidered. Different controllers are used to control the speed and power of this turbine. In fact, four regulators PID ZN, FLC, FLC-PID and 
hybrid were tested by simulation. The results obtained showed clearly that the FLC-PID and the hybrid controllers have the best performances in terms of time response and steady state error. These controllers will be used in future works to study the behavior of a gas turbine connected to a grid.

\section{REFERENCES}

[1] G. Shankar, V. Mukherjee, "load-following performance analysis of a microturbine for islanded and grid connected operation, electrical power and energy systems," 55 (2014) 704-713, Elesevier.

[2] L. N. Hannett, A. Khan, "Combustion Turbine Dynamic Model Validation from Tests, IEEE Transactions on Power Systems," Vol. 8, No. 1, February 1993.

[3] W. I. Rowen, "Simplified mathematical representations of heavy-duty gas turbines," ASME J. Eng. Power, Vol. 105, pp. 865-869, 1983.

[4] A. M. Mansourabad, M.T.H. Beheshti and M. Simab, "A hybrid pso_fuzzy_pid controller for gas turbine speed control," International Journal of Control and Automation Vol. 6, No. 1, February, 2013.

[5] F. Jurado, M. Ortega, and A. Cano, "Predictive Control of Matrix Converter based Micro-Turbine Electric Power Components and Systems," 36:409-431, 2008 Copyright Taylor \& Francis Group, LLC.

[6] F. Jurado, "Study of molten carbonate fuel cell- microturbine hybrid power cycles," Journal of Power Sources 111 (2002) 121-129.

[7] F. Jurado, A. Cano, J. Carpio, "Biomass based micro-turbine plant and distribution network stability Energy Conversion and Management," 45 (2004) 2713-2727.

[8] W. I. Rowen, "Simplified mathematical representation of single shaft gas turbines in mechanical drive services," presented at the Int. Gas Turbine and AreoengineCongr and Expo, Colonge, Germany, 1992.

[9] J.W. Kim and S. W. Kim, "Design of Incremental Fuzzy PI Controllers for a Gas-Turbine Plant," IEEE/Asme transactions on mechatronics, vol. 8, no. 3, September 2003.

[10] H. E. Shalan, M. A. Moustafa Hassan, A. B. G. Bahgat, "Parameter Estimation and Dynamic Simulation of Gas Turbine Model in Combined Cycle Power Plants Based On Actual Operational Data," Journal of American Science, 2011.

[11] I. Yousefi, M. Yari and M-A Shoorehdeli, "Modeling, Identification and Control of a Heavy Duty Industrial Gas Turbine," (C) 2013 IEEE.

[12] L. Meegahapola, Member, IEEE, and D- Flynn, Senior Member, IEEE, Characterization of Gas Turbine Lean Blowoutduring Frequency Excursions in Power Networks," in IEEE Transactions on Power Systems 30(4):1877$1887 \cdot$ July 2015.

[13] L. Meegahapola, Member, IEEE, and D- Flynn, Senior Member, IEEE, "Characterization of Gas Turbine Lean Blowout during Frequency Excursions in Power Networks," IEEE transactions on power systems, 0885-8950 C 2014 IEEE.

[14] F. Jurado, J. Carpio, "Improving distribution system stability by predictive control of gas turbines," Energy Conversion and Management 47 (2006) 2961-2973, science direct.

[15] L. Meegahapola, "Characterisation of gas turbine dynamics during frequency excursions in power networks," Published in IET Generation, Transmission \& Distribution Received on 16th November 2013, and IEEE.

[16] X.f Zhang, J. Liu, and Z.J. Wang, "An Immune Bidirectional Regulation-Based Decoupling Control in Single Shift Gas Turbine Plant," 2009 Third Asia International Conference on Modelling\& Simulation C 2009 IEEE.

[17] S. Balamurugan, N. Janarthanan, K.R.M. V. Chandrakala, "Small and large signal modeling of heavy duty gas turbine plant for load frequency control Electrical Power and Energy Systems,", Sciencedirect2016 Elsevier.

[18] O. Sullivan, J.O. Malley, M. J., "Identification and validation of dynamic global load model parameters for use in power system simulation," IEEETransactions on Power Systems, Vol. 11, 1996, pp. 851-857.

[19] X. Xu, R. M. Mathur, J. Jiang, G. J. Rogers, and P. Kundur, "Modeling Effects of System Frequency Variations in Induction Motor Dynamics Using Singular Perturbations," IEEE Transactions on Power Systems, vol. 15, no. 2, pp. 764-770, May 2000.

[20] H. Rashid. AL-Rubayi, G. L. Ibrahim, "Comparison of Transient Stability Response for MMPS using UPFC with PI and Fuzzy Logic Controller," (IJEEI) Vol. 7, No. 1, Sep 2019, pp. 432 440.

[21] Z. Y. Zhao, Member, IEEE, M. Tomizuka, Member, IEEE, and S. Isaka, Member, IEEE, "Fuzzy Gain Scheduling of PID Controllers," IEEE transactions on systems, man and cybernetics. vol. 23, no.5. September 1993.

[22] J. Ziegler, N. Nichols, "Optimum setting for automatic controllers," Trans ASME 1942; 64:759-68.

[23] A.A Fahmya, A.M Abdel Ghany, "Adaptive Functional-Based Neuro-Fuzzy-PID Incremental Controller Structure," Indonesian Journal of Electrical Engineering and Informatics (IJEEI) Vol. 2, No. 1, March 2014, pp. 24 47 ISSN: 2089-3272.

[24] J.J.Buckley, "Universal fuzzy controllers,” Automatica, Copyright (C) 1992 Published by Elsevier Ltd.

[25] S.Balamurugan,N.Janarthanan, K.R.M.Vijaya Chandrakala“Small and large signal modeling of heavy duty gas turbine plant for load frequency control,"by Elsevier July 2016.

[26] A. Fakharian, R. Mosaferin, and M. B. Menhaj, "A New Recurrent Fuzzy Neural Network Controller Design for Speed and Exhaust Temperature of a Gas Turbine Power Plant," AIJ-MISC, Vol. 46 - No. 2 - Fall 2014, pp. 23 - 30. 


\section{BIOGRAPHY OF AUTHORS}
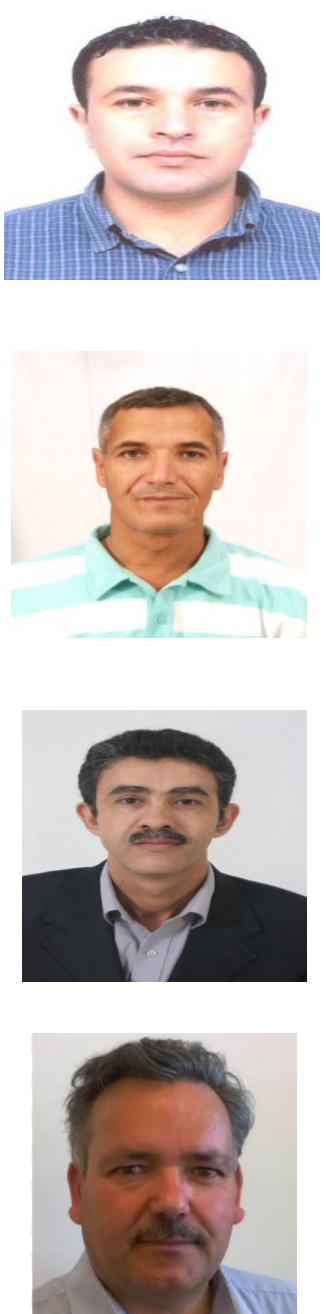

Lyes ABBASSEN received his BSc degree and his Magister in electrical engineering from Mouloud Mammeri University, Tizi-Ouzou, Algeria, in 2007, 2011 respectively. He is currently a $\mathrm{PhD}$ student at the same university. His research interests include modelling, control and analysis of different power plant STG-GTG and combined cycle, control systems and renewable energy resources. I held the position of Electrical Engineer Project at SONATRACH Algiers Refinery Algeria 2011-2019, and currently I hold the position of Instrumentation Engineer researcher at SONATRACH Central Direction of Research and Development DC-R\&D Boumerdes -Algeria.

Nacereddine BENAMROUCHE received his $\mathrm{PhD}$ degree in electrical engineering from the University of Sheffield UK in 1990. He worked as a teaching assistant at The University of Leeds 1990-1991, and as head of department at Najran College of Technology, Saudi Arabia from 20002004. He is currently Professor at the Electrical Engineering and Computing Faculty, University of Tizi ouzou, Algeria, where he occupied the chair of Vice chancellor for post graduate studies and research between 2007-2010. He is appointed as Laboratory Director of Advanced Technologies in Electrical Engineering since Mars 2011. His research interests include electrical machines and drives, control systems and renewable energy sources.

Mustapha Zaouia was born in Tizi-Ouzou, Algeria. He received his Magister degree from Polytechnic School, Algiers, Algeria in 2001and his PhD degree in the Mouloud Mammeri University of Tizi-Ouzou, Algeria. He works as an assistant Professor at the same university. His research interests are the electromagnetic-mechanical modelling, numerical simulation of electromagnetic machines particularly the linear machines and permanent-magnet machines applied to the electrical and hybrid vehicles.

Amar Bousbaine was born in Bouira in 1960. He received his Bsc, MSc and PhD respectively at the University of Tizi Ouzou in 1985 and at the University of Strathclyde in 1990 and at the University of Sheffield in 1995. He is currently reader in Electronics in the college of Engineering and Technology at the university of Derby, UK. He is also an active researcher in the field of power system for electric vehicules, renewable energy sources, hydrogen fuel cells and autonomous control for drives. He published over 70 papers in referred journal. 